\title{
Economics research in Spain during the 1990s: a literature review
}

\author{
Javier Ruiz-Castillo
}

\begin{abstract}
This paper reviews the results of the literature on the ranking of centers of excellence in economics. There are two objectives: (1) to examine the evolution during the 1990s of certain features of economics research — such as the gap that exists between the US and the rest of the world, the dominant position of the UK within Europe, and the low productivity of economic scholars everywhere-and (2) to document the significant progress that Spanish research institutions have experienced during this period. Results by several broad fields of specialization are summarized here for the first time.
\end{abstract}

Keywords Economics research $\cdot$ Rankings $\cdot$ US-Europe gap

\section{Introduction}

Traditionally, the ranking of economics departments according to their research performance was an issue only in the United States and, only occasionally, in some European countries (for references to this literature, see Combes and Linnemer 2002; or García-Castrillo et al. 2002; and for recent work about the United States, see Scott and Mitias 1996; Dusansky and Vernon 1998; Griliches and Einav 1998). Later, several 
papers were published on Europe as a whole (Hirsh et al. 1984; Kirman and Dahl 1994); among those, the influential contribution of Kalaitzikakis et al. (1999), which deals with the 1991-1996 period and was corrected and updated for 1997-2002 by Tombazos (2005), should be emphasized. However, the real change took place when the EEA (European Economic Association), concerned with poor governance and the reduced role given to research criteria in the financing of the majority of non-British European universities, held a competitive selection process in 1999 for the ranking of economics departments in Europe and their comparison with the best centers in the United States. Out of the eight proposals, the following four were selected: (i) Combes and Linnemer; (ii) Coupé; (iii) Kalaitzidakis, Mamuneas and Stengos, and (iv) Lubrano, Bauwens, Kirman and Protopopescu. After the usual anonymous evaluation process, the results were published in the December 2003 issue of the Journal of the European Economic Association. Other comparable studies-such as García-Castrillo et al. (2002), the electronic publication Econphd (2004), and the study carried out by the European Union Research Directorate General referred to as European Commission (2004)—also appeared around that time.

We believe that the time is ripe for a review of the results that this literature contains on the evolution of the economics research carried out in Spanish institutions during the 1990s and the first years of the present century. The restriction to this period is justified by the abundance of information, the scarcity of Spanish research in periods prior to this time, and the opportunity to include the results obtained by strongly research-oriented Spanish universities, such as Pompeu Fabra and Carlos III, established at the beginning of this period. Although the paper's focus is on quality research in the international context, it also reviews the literature dealing with the evolution of Spanish research in a national context. ${ }^{1}$

In any survey of this literature it should be considered informative-and even obligatory - to place the research which has been carried out in a given country within an international context. Thus, this paper has two aims: (1) to briefly review the evolution during the 1990s of three characteristic features of economic research, namely, (a) the existing gap between the US and the rest of the world, (b) the predominance of the UK within Europe, and (c) the low productivity of economics scholars everywhere; and (2) to document the dramatic progress experienced by Spanish research centers during this time (for an excellent discussion of points (a) and (b) above, see the review paper by Drèze and Estevan 2007, which appeared when this one was already in progress).

We shall only be concerned with articles published in academic journals with an anonymous peer-evaluation process that is the essence of quality control in any scientific discipline (For a critical view of this option see, for example, Nederdof 1989, and Nederdof and van Raan 1993). Even with this narrow focus, it is important to establish from the beginning that there is no single evaluation system that is completely satisfactory for all conceivable purposes. As stated by the committee members of the EEA in charge of selecting the four abovementioned papers, "In principle, the ideal may be

\footnotetext{
${ }^{1}$ We are referring to García et al. (1999a), Bergantiños et al. (2002), Dolado et al. (2003), Royuela et al. (2006), and Rodriguez (2006). Sanz Casado et al. (1999) refer only to the first part of the period studied here, whereas García et al. (1999b) and Pons and Tirado (1999) concentrate on publications in Spanish journals.
} 
a single widely accepted index of every department's research output. However, given the many legitimate areas of disagreement on how an index should be computed, this ideal seems unattainable for the present" (Neary et al. 2003, p. 1240). Consequently, it will be often necessary to review the robustness of the results obtained with a battery of imperfect indicators.

From a methodological point of view, it is useful to start from the volume of published articles in the academic journals included in large international databases - such as EconLit, a publication of the American Economic Association, or the Economics section of the SSCI (Social Science Citation Index) produced by the ISI (Institute of Scientific Information). However, it is important to incorporate other dimensions that, in principle, can drastically alter any ranking based exclusively on the raw volume of publications. The more controversial topics are the selection of the set of journals that will be eventually taken into account, as well as the adjustments to be made on account of the quality of the articles, which is usually identified with the quality of the journals in which they are published.

In order to facilitate the interpretation of the results, the studies reviewed in this paper are informally ranked from greater to lesser degrees of "egalitarianism". A methodology is considered more egalitarian the lower the weight it assigns to the "best" journals, recognized as such by a large majority of the profession, in comparison with the next tier of journals with international impact, and the higher the score it gives to "local" publications with a national or a smaller audience.

The paper focuses on results rather than methods, and the main findings are the following:

(1) Although the gap between the US and Europe narrowed during the 1990s, the US is still responsible for more than half the volume of worldwide production, and approximately two thirds of the total number of pages adjusted by differences in quality and other concepts published by the top 200 universities worldwide. Similarly, at the end of the last century, among the top 200, 100, and 20 economic departments in the world the proportion represented by the United States is 45 , 55 , and 95\%, respectively (see Tables 1, 2, 3, 4).

(2) Within Europe, two facts deserve to be emphasized. First, the UK maintains a dominant position. Second, among the success stories during the 1990s, Spain shows the largest yearly growth rate in publications volume. After the adjustment for quality and other factors, Spain jumps to the fourth European position after the UK, The Netherlands, and France (see Table 5).

(3) The distribution of the scientific publications in economics is very unequal everywhere. The researchers and research centers that regularly contribute something to the research output, however measured, constitute a minority in their respective countries. According to all available indicators, this phenomenon is even more pronounced in Spain than elsewhere.

(4) As the degree of egalitarianism in the methodology used drops and more recent periods are considered, five of the most active Spanish institutions in publication volume become part of the international big leagues. These are the UAB (Universidad Autónoma de Barcelona) plus the IAE (Instituto de Análisis Económico)— grouped as a single center-UPF, UCIII and UAL (Universidad Pompeu Fabra, 
Universidad Carlos III, and Universidad de Alicante, respectively) and CEMFI (Centro de Estudios Monetarios y Financieros). The first three finished out the twentieth century in 48th to 80th place in the world and 9th to 14th in Europe, whereas the next two place around 100th to 140th on a world level and 30th to 50th in Europe (see Tables 6, 7, 8).

(5) As summarized here for the first time, in several broad fields of specialization some of these Spanish institutions are very highly placed. According to Econphd (2004), in Econometrics the UCIII occupies the 10th place in the world and second in Europe; in Public Economics the UAB-IAE is placed 14th in the world and second in Europe, while in Macroeconomics the UPF is placed 24th in the world and 6th in Europe (see Table 10).

The rest of this paper is organized in four sections and an Appendix. The following section reports the main solutions found in the literature to key methodological issues whose discussion is relegated to the Appendix. "The world and Europe during the 1990s" section presents evidence regarding the best research centers on a worldwide and a European scale. "Spain" section reviews the Spanish situation for general economics, as well as in broad research fields. "Conclusions" section includes some comments on the features shared by all Spanish institutions that made it into the international rankings.

\section{A summary of alternative methodologies}

We are interested in determining the most productive economics departments in Spain, Europe and the world. Unfortunately, there is still no generally accepted single ranking based on the information about academic publications contained in the available datasets. The Appendix contains a discussion of some key methodological issues, while this Section summarizes the main features of the solutions to these questions found by the majority of the papers under review.

First, independently of how the research output of individual scholars is measured, the aggregate score for all members of an institution indicates its global strength but favors the larger departments. For reasons discussed in the Appendix, except for Combes and Linnemer (2003) the rest of the studies provide only the total score of each center. Therefore, this will be the classification criterion used in the rest of the paper.

Second, given that we wish to rank economic departments according to their publications, where should an author's articles be accounted for? In the institution s/he is affiliated with at the time of publication (flow), or only in the institution where s/he is working at present (stock)? In the first case, an author's publications are credited to the department to which s/he belongs in the year of publication of each article. In the second case, all the publications of an author are credited to the department s/he belongs to at present. As will be seen below, most methods take a flow option that is the easiest to perform.

In order to review the remaining problems, it is useful to refer to Van Damme's (1996) well-known formula for calculating the score, $S_{i}$, of researcher $i$ in a given year: 


$$
S_{i}=\sum_{P_{i}}\left[\beta\left(P_{i}\right) \mathrm{w}\left(P_{i}\right)\right] / \alpha\left(P_{i}\right) .
$$

For each publication $P_{i}, \beta\left(P_{i}\right)$ denotes the length of the article; $w\left(P_{i}\right)$ is a weight that reflects the publication's quality, and $\alpha\left(P_{i}\right)$ is a correction coefficient for the existence of several co-authors (or an author belonging to several institutions).

Longer articles are not necessarily better. Nevertheless, there seems to be a general agreement as to the correlation between the length of an article and its importance. For this reason, except for the European Commission (2004) and Lubrano et al. (2003) who set $\beta\left(P_{i}\right)=1$, the rest of the studies take into account the number of pages in each article. As a matter of fact, many also consider the differences in the number of characters per page in each journal and convert each article into the number of pages of a paper in a reference journal.

As far as co-authorship is concerned, except for the European Commission (2004) and Lubrano et al. (2003) who set $\alpha\left(P_{i}\right)$ equal to one or the square root of the number of authors of $P_{i}$, respectively, the rest of the studies set $\alpha\left(P_{i}\right)$ equal to the number of authors of $P_{i}$. Similarly, if an author states that s/he belongs to $m$ research centers in a given year, the score that the majority of the papers allocate to each one of them in this year is $S_{i} / m$, where $S_{i}$ is determined in accordance with Eq. (1).

Finally, there is the classification of the available methods along an elitism-egalitarian axis, an issue closely related to the procedures followed to determine the quality of each item $P_{i}$. All methods agree on identifying the quality of an article with the quality of the academic journal in which it is published. Beyond that, the next relevant decision is regarding the set of journals to be considered: the smaller the number of them, the more elitist the method is bound to be. The final step is how to construct a set of weights $w_{j}=w\left(P_{i}\right)$ for all articles $P_{i}$ in each journal $j$. As discussed in the Appendix, there are two alternatives: one can use objective criteria based on the number of times the articles of a given journal are cited, or one can rely on the opinion of experts. In either case, the ranking of methods according to their degree of egalitarianism depends on two aspects: the weight granted to the small number of the "best" journals in comparison with the next tier of journals with an international impact, and the awarding of a score or the exclusion of the "local" journals from a national level or a lower tier. As pointed out in the Introduction, a methodology is considered more egalitarian the lower the weight it assigns to the "best" journals, and the higher the score it gives to "local" publications. An ordinal scheme with seven classes, from a "very low" to a "maximum" degree of egalitarianism, is finally arrived at.

For the seven flow methods and the three stock ones used in this paper, Table 11 in the Appendix provides a schematic comparison in terms of the treatment of publication length, co-authorship, and the factors influencing the degree of egalitarianism.

\section{The world and Europe during the 1990s}

This Section has three aims. First, to document the evolution during the 1990s of the gap between the research in economics done in the US, Europe and the rest of the world. Second, to review two issues within Europe: the dominant role of the United Kingdom, and the surge of Spanish research during this decade. Third, to summarize 
Table 1 The gap between the US and Europe among top economics departments in the world according to different studies and periods

\begin{tabular}{|c|c|c|c|c|c|c|c|c|}
\hline \multirow[t]{2}{*}{$\begin{array}{l}\text { No. of Journals: } \\
\text { Egalitarianism: } \\
\text { Period: }\end{array}$} & \multicolumn{2}{|l|}{$\begin{array}{l}\text { G-Castrillo } \\
55 \\
\text { Medium } \\
\text { 1992-1997 }\end{array}$} & \multicolumn{2}{|l|}{$\begin{array}{l}\text { Coupé } 1 \\
- \\
\text { Medium/high } \\
\text { 1990-2000 }\end{array}$} & \multicolumn{2}{|c|}{$\begin{array}{l}\text { Kalaitzidakis } 1 \\
30 \\
\text { Low } \\
1995-1999\end{array}$} & \multicolumn{2}{|l|}{$\begin{array}{l}\text { Econphd } \\
63 \\
\text { High } \\
1993-2003\end{array}$} \\
\hline & No. of Dpts. & $\%$ & No. of Dpts. & $\%$ & No. of Dpts. & $\%$ & No. of Dpts. & $\%$ \\
\hline United States & 122 & 61.0 & 103 & 51.5 & 97 & 48.5 & 87 & 44.5 \\
\hline Europe & 50 & 25.0 & 55 & 27.5 & 62 & 31.0 & 73 & 36.5 \\
\hline Rest & 28 & 14.0 & 42 & 21.0 & 41 & 20.5 & 40 & 20.0 \\
\hline Total & 200 & 100.0 & 200 & 100.0 & 200 & 100.0 & 200 & 100.0 \\
\hline United States & 70 & 70.0 & 65 & 65.0 & 53 & 53.0 & 59 & 59.0 \\
\hline Europe & 15 & 15.0 & 19 & 19.0 & 31 & 31.0 & 28 & 28.0 \\
\hline Rest & 15 & 15.0 & 16 & 16.0 & 16 & 16.0 & 23 & 23.0 \\
\hline Total & 100 & 100.0 & 100 & 100.0 & 100 & 100.0 & 100 & 100.0 \\
\hline United States & 40 & 80.0 & 41 & 82.0 & 35 & 70.0 & 35 & 70.0 \\
\hline Europe & 4 & 8.0 & 6 & 12.0 & 7 & 14.0 & 10 & 20.0 \\
\hline Rest & 6 & 12.0 & 3 & 6.0 & 8 & 16.0 & 5 & 10.0 \\
\hline Total & 50 & 100.0 & $\mathbf{5 0}$ & 100.0 & 50 & 100.0 & $\mathbf{5 0}$ & 100.0 \\
\hline
\end{tabular}

the evidence on the high degree of concentration of the output produced by academic researchers everywhere, and especially within Spain.

The worldwide scene

There is a chronic concern in the European front regarding the distance that separates our Continent from the US in every dimension relating to science, research, and development. From this perspective, it is useful to establish how the worldwide position of the US in the field of economics research has evolved.

There are four papers ranking academic departments on a worldwide scale during the last decade of the past century: García Castrillo et al. (2002), who rank 1,000 institutions for the period 1992-1997; Coupé (2003) and Kalaitzidakis et al. (2003) who rank 200 Departments for the periods 1990-2000 and 1995-1999, respectively, and Econphd (2004), which refers to 321 centers during the period 1993-2003. First, we look at the ranking of top economics departments in the world. Second, we consider quantitative evidence of two types: the volume of publications, and the number of standardized pages adjusted by a number of concepts, including the relative quality of academic journals.

As can be seen in Table 1, the proportion represented by the US in the top 200 departments during the period drops from 61 to $45-48 \%$. The European share increases from 25 to $31-36 \%$, and the rest of the world goes from 25 to $31-36 \%$. However, as we proceed towards the best 50, the dominant position of the US strengthens even more so and falls at a declining rate over the period. Table 2 presents the top 20 universities 
Table 2 The top 20 economics departments in the world according to different studies and periods, ordered by the Coupé 3 Criterion (that takes into account the ten best journals selected in Kalaitzidakis et al. 1999, or Kalaitzidakis 2)

\begin{tabular}{|c|c|c|c|c|c|}
\hline $\begin{array}{l}\text { No. of Journals: } \\
\text { Egalitarianism: } \\
\text { Period: }\end{array}$ & $\begin{array}{l}\text { Coupé } 3 \\
10 \\
\text { Very low } \\
1990-2000\end{array}$ & $\begin{array}{l}\text { Coupé } 2 \\
71 \\
\text { High } \\
1990-2000\end{array}$ & $\begin{array}{l}\text { Coupé } 1 \\
- \\
\text { High/medium } \\
\text { 1990-2000 }\end{array}$ & $\begin{array}{l}\text { Kalaitzidakis } 1 \\
30 \\
\text { Low } \\
1995-1999\end{array}$ & $\begin{array}{l}\text { Econphd } \\
63 \\
\text { High } \\
1993-2003\end{array}$ \\
\hline \multicolumn{2}{|c|}{ 1. Harvard University } & 1 & 1 & 1 & 1 \\
\hline \multicolumn{2}{|c|}{ 2. University of Chicago } & 2 & 2 & 2 & 2 \\
\hline \multicolumn{2}{|l|}{ 3. MIT } & 3 & 5 & 3 & 3 \\
\hline \multicolumn{2}{|c|}{ 4. Northwestern University } & 5 & 7 & 4 & 7 \\
\hline \multicolumn{2}{|c|}{ 5. Stanford University } & 4 & 4 & 8 & 6 \\
\hline \multicolumn{2}{|c|}{ 6. Princeton University } & 7 & 11 & 7 & 5 \\
\hline \multicolumn{2}{|c|}{ 7. University of Pennsylvania } & 6 & 3 & 5 & 8 \\
\hline \multicolumn{2}{|l|}{ 8. Yale University } & 9 & 8 & 6 & 9 \\
\hline \multicolumn{2}{|c|}{ 9. U. of California, Berkeley } & 8 & 6 & 9 & 4 \\
\hline \multicolumn{2}{|c|}{ 10. Columbia University } & 10 & 10 & 11 & 13 \\
\hline \multicolumn{2}{|c|}{ 11. U. of California, Los Angeles } & 13 & 12 & 14 & 11 \\
\hline \multicolumn{2}{|c|}{ 12. New York University } & 2 & 13 & 10 & 10 \\
\hline \multicolumn{2}{|c|}{ 13. University of Michigan } & 11 & 9 & 13 & 15 \\
\hline \multicolumn{2}{|c|}{ 14. University of Rochester } & 14 & 20 & 17 & 16 \\
\hline \multicolumn{2}{|c|}{ 15. U. of California, San Diego } & 17 & 28 & 12 & 21 \\
\hline \multicolumn{2}{|c|}{ 16. Boston University } & 20 & 30 & 22 & 26 \\
\hline \multicolumn{2}{|c|}{ 17. University of Toronto } & 22 & 25 & 23 & 36 \\
\hline \multicolumn{2}{|c|}{ 18. University of Tel Aviv } & 28 & 42 & 26 & 30 \\
\hline \multicolumn{2}{|c|}{ 19. London School of Economics } & 23 & 15 & 20 & 12 \\
\hline \multicolumn{2}{|c|}{ 20. Carnegie Mellon University } & 25 & 32 & 30 & 40 \\
\hline \multicolumn{2}{|c|}{ 21. University of Wisconsin } & 21 & 16 & 19 & 13 \\
\hline \multicolumn{2}{|c|}{ 22. University of Texas } & 19 & 21 & 16 & 19 \\
\hline \multicolumn{2}{|c|}{ 23. Cornell University } & 16 & 14 & 15 & 14 \\
\hline \multicolumn{2}{|c|}{ 25. Duke University } & 15 & 17 & 27 & 35 \\
\hline \multicolumn{2}{|c|}{ 26. University of Maryland } & 24 & 19 & 31 & 17 \\
\hline \multicolumn{2}{|c|}{ 30. Ohio State University } & 18 & 18 & 38 & 23 \\
\hline \multicolumn{2}{|c|}{ 34. University of British Columbia } & 29 & 27 & 29 & 20 \\
\hline \multicolumn{2}{|c|}{ 41. University of Toulouse } & 51 & 73 & 46 & 18 \\
\hline \multicolumn{2}{|c|}{ 63. Tilbug University } & 56 & 47 & 18 & 24 \\
\hline
\end{tabular}

according to the following five rankings: the three variants of Coupé, Kalaitzidakis 1, and Econphd. Universities are ranked in accordance with the criterion referred to as Coupé 3 or Kalaitzidakis 2, that is, the elitist classification that only takes into account the top ten journals. The main result is that the robustness at the world's top leaves little room for doubt.

- Harvard, Chicago and MIT occupy the top three spots, while Northwestern and Stanford appear at least three times (of the five cited) in the 4th and 5th positions. 
Table 3 Evolution of the articles published during the 1990s in the US, the EU-15, Japan and the rest of the world

\begin{tabular}{lrrrc}
\hline & 1991 & 1996 & \multicolumn{1}{c}{2001} & Growth rate 1991-2001 in \% \\
\hline Total number of articles in the world & 6,201 & 6,869 & 7,823 & 2.35 \\
Percentages in & & & & \\
United States & 66.5 & 59.2 & 53.0 & -2.23 \\
European Union-15 & 21.7 & 31.8 & 39.5 & 6.16 \\
Japan & 1.6 & 1.7 & 2.2 & 3.11 \\
Rest of the world & 10.2 & 7.3 & 5.3 & - \\
& 100.0 & 100.0 & 100.0 & \\
\hline
\end{tabular}

Source: ISI, National Science Indicator

Reference: Table 2.1, Chap. II, European Commission (2004)

Table 4 Percentage distribution by large areas of the number of adjusted pages published in 30 top journals during 1995-1999 in the first 200 departments of the world

\begin{tabular}{lr}
\hline United States & 65.0 \\
European Union-15 & 21.2 \\
Rest of the world & 13.8 \\
Total & 100.0 \\
\hline
\end{tabular}

Source: Table 3 in Kalaitzidakis et al. (2003, p. 1357)

- Princeton and Pennsylvania, as well as Yale, Berkeley and Columbia, appear at least three times in the 6th to 10th positions. The University of California at Los Angeles, New York University and the University of Michigan hold the 11th to 13th positions.

- The University of Rochester, the University of California at San Diego, LSE (London School of Economics), Cornell, the University of Wisconsin, the University of Texas, and Boston University round out the top 20.

The alterations in this ranking due to methodological differences or to the period of time covered only affect the relative position of the universities in the top 15 positions. ${ }^{2}$ On the other hand, it must be pointed out that, although the Universities of Toronto, Tel Aviv, British Columbia or, most recently, Toulouse and Tilburg appear on occasion, only one non-US university, the LSE, is consistently ranked in the top 20. However, there is no European institution in the top 10 positions.

Tables 3 and 4 present some quantitative evidence. Table 3 is based on the NSI (National Science Indicator), another product of the ISI that covers fewer journals than the SSCI (see Table 3). It summarizes the evolution in the volume of articles published by the US, the 15 member states of the EU, Japan and the world as a whole

\footnotetext{
${ }^{2}$ Seventeen of these Universities, including the LSE, are also in the top 20 in the world according to García-Castrillo et al. (2002) for the period 1992-1997. As far as the ranking is concerned, the only differences worth mentioning are the improvements experienced by the University of Pennsylvania and the University of Wisconsin.
} 
during the 1991-2001 period. The superiority of the US at the beginning of this period is clear: in 1991, research in this country comprised $66.5 \%$ of the total, whereas that of the EU - 15 made up $21.7 \%$. Nevertheless, during the 1990s the growth rate for the US was negative $(-2.2 \%)$, while that of Europe was $6.2 \%$, which considerably narrowed the gap between the two areas. Thus, in 2001 the US and Europe comprised 53 and $39.5 \%$ respectively, of world research.

It is important to evaluate research excellence beyond the mere volume of publications taking into account the quality of academic journals, as well as the methodological complications mentioned in "A summary of alternative methodologies" section. For that purpose, Table 4 presents the evidence on the number of pages adjusted by different concepts according to Kalaitzidakis 1, which is based on publications appearing in the period 1995-1999 in the top 30 journals. Of the total number of pages published by the top 200 universities worldwide, approximately two-thirds are attributable to US institutions. The European percentage drops to little more than $20 \%$.

It must be concluded that the gap between the US and Europe remains quite formidable. Furthermore, the more stringent the criteria for excellence used in the comparison, the wider the gap becomes.

\section{The European scene}

In order to review the research performance of the different European countries, two types of evidence will be presented: first, the sheer volume of publications during the 1990s in relation to that of the world as a whole according to the NSI (see the left-hand side of Table 5); second, the distribution by country in 1995-1999 of the best 75 European departments, as well as the number of adjusted pages they produce according to Kalaitzidakis 1 (right-hand side of Table 5).

Two facts deserve emphasizing. First, in the early 1990s the UK is responsible for nearly $10 \%$ of the world output and $45.2 \%$ of the European production (the last figure is not shown in Table 5). In 2001 the percentage that this country represents in the world increases to $14.4 \%$. Nevertheless, due to the fact that other European countries advanced at a quick pace, the UK's contribution in Europe remains constant (see column 4 in Table 5). On the other hand, the 19 departments of the UK that represent somewhat more than $25 \%$ of the top 75 in Europe, are responsible for one third of the total production.

Second, the best description of Spain's improvement in the volume of publications is contained in the following quotation from the European Commission (2004, Chap. III, p. 37): "Spain is one of the largest producers of scientific publications in economics. Between 1991 and 2001, its presence in the ISI databases increased from $0.4 \%$ to $2.7 \%$, thus achieving the greatest yearly growth rate $(20.3 \%)$ of all European countries. EconLit shows some impressive increases as well (the EconLit information is not shown here): between 1991 and 1999, Spanish publications increased from 80 to 400 , which represents an annual average increase of $23.4 \%$. Spain's percentage contribution rose to $11.5 \%$, the highest rate in Europe. Spain has gone from being the sixth lowest producer of literature in 1991 (according to EconLit) to being the sixth largest producer in 1999". 
Table 5 Percentage distribution of the articles published during the 1990s in the EU, and of the top 75 departments in 30 top journals according to Kalaitzidakis 1

\begin{tabular}{|c|c|c|c|c|c|c|c|}
\hline \multicolumn{5}{|c|}{ Percentage distribution of the articles published } & \multicolumn{3}{|l|}{ Kalaitzidakis 1} \\
\hline & \multicolumn{4}{|c|}{ Relative to the world } & & \multirow[b]{2}{*}{$\begin{array}{l}\text { Top } 75 \\
\text { depts } \%\end{array}$} & \multirow[b]{2}{*}{$\begin{array}{l}\text { Adjusted } \\
\text { pages \% }\end{array}$} \\
\hline & $\begin{array}{l}1991 \\
\%\end{array}$ & $\begin{array}{l}2001 \\
\%\end{array}$ & $\begin{array}{l}\text { Growth rate } \\
\%\end{array}$ & $\begin{array}{l}\text { Relative to Europe in } 2001 \\
\%\end{array}$ & & & \\
\hline $1 \mathrm{UK}^{\mathrm{a}}$ & 9.8 & 14.4 & 3.9 & 45.3 & 1 United Kingdom & 26.6 & 33.3 \\
\hline 2 Germany & 2.1 & 4.4 & 7.9 & 13.8 & 2 Holland & 9.3 & 13.8 \\
\hline 3 Holland & 2.0 & 3.9 & 6.8 & 12.3 & 3 France & 12.0 & 11.0 \\
\hline 4 France & 1.8 & 3.6 & 7.3 & 11.3 & 4 Spain & 5.3 & 9.3 \\
\hline 5 Italy & 1.2 & 2.8 & 8.9 & 8.8 & 5 Germany & 9.3 & 5.4 \\
\hline 6 Spain & 0.4 & 2.7 & 20.3 & 8.5 & 6 Italy & 8.0 & 4.6 \\
\hline 7 Belgium & 0.9 & 1.7 & 7.0 & 5.3 & 7 Sweden & 5.3 & 5.1 \\
\hline 8 Sweden & 1.0 & 1.7 & 4.9 & 5.3 & 8 Belgium & 2.7 & 4.2 \\
\hline 9 Denmark & 0.7 & 1.2 & 6.2 & 3.8 & 9 Switzerland & 5.3 & 2.8 \\
\hline 10 Finland & 0.5 & 1.0 & 7.2 & 3.1 & 10 Denmark & 2.7 & 2.5 \\
\hline 11 Austria & 0.6 & 0.7 & 0.9 & 2.2 & 11 Norway & 4.0 & 2.3 \\
\hline 12 Greece & 0.4 & 0.6 & 5.6 & 1.9 & 12 Other countries ${ }^{b}$ & 9.5 & 8.2 \\
\hline 13 Ireland & 0.2 & 0.5 & 6.6 & 1.6 & Total & 100.0 & 100.0 \\
\hline 14 Portugal & 0.1 & 0.5 & 19.5 & 1.6 & & & \\
\hline 15 Luxembourg & 0.1 & 0.0 & -7.2 & 0.0 & & & \\
\hline Europe & 21.7 & 31.8 & & 100.0 & & & \\
\hline
\end{tabular}

Source: Left-hand Panel: ISI, Nacional Science Indicator. European Commission (2004, Chap. II, Table 2.1)

Right-hand panel: Kalaitzidakis et al. (2003, Table 4)

${ }^{\text {a }}$ Countries appear in order of their percentage contribution to the world total in 2001

b Austria, Cyprus, Finland, Greece, Ireland, Portugal and Turkey, each one contributing one Department to the top 75 in Europe

Spain (together with Belgium) also stands out because of its good performance in quality research: about $5 \%$ of the best 75 departments generate more than $9 \%$ of the total output (see the right-hand side in Table 5). The Netherlands, a small country, is another success story: it provides close to $10 \%$ of the departments and $14 \%$ of the adjusted pages. Other European countries, however, are less productive. France, Sweden and Denmark, for example, produce somewhat less than what would be expected from their share of the top 75 departments, while Germany, Italy, Switzerland and Norway do much worse. Thus, Spain, which was the sixth country in volume of publications within Europe, is now clearly in fourth position behind the UK, The Netherlands and France when adjusted pages are taken into account. ${ }^{3}$

\footnotetext{
3 The worldwide contribution of Spain according to Kalaitzidakis 1 is $2.05 \%$ (slightly below the $2.7 \%$ of the world volume of publications in 1999 shown in the left-hand panel of Table 5).
} 
It will be illuminating to close this Section with a brief discussion of one of the features of economic research highlighted in Villar's (2003) survey: no matter what geographical area we refer to, the productivity of academic economists (university faculty and scholars in research centers) is quite low. For our purposes, it will suffice to provide a few glimpses of this phenomenon (for a more detailed analysis, see Villar 2003; or Ruiz-Castillo 2006b).

In Coupé's (2003) study, it is found that 32,740 authors, or $59.5 \%$ out of a total of 55,000, wrote (alone or in collaboration) only one article in EconLit during 19941998. Similarly, according to Combes and Linnemer (2003) only $42.8 \%$ of European academic economists published at least once in a journal listed in EconLit during 1971-2000. Moreover, according to Lubrano et al. (2003), only $21.1 \%$ of the authors who did appear at least once in EconLit from 1990 to 2000 and one third of their departments exceed some minimum standards of production (the standard for a researcher is one article with a co-author published in the space of a decade in the American Economic Review or the equivalent in other journals; the standard for a department is set equal to that of 10 researchers).

The Spanish figures point to a rather dismal average performance. According to Combes and Linnemer (2003), only $28 \%$ of academic economists published at least once in EconLit during 1971-1990. Of the authors that appear in that database in 1990-2000, only $16.5 \%$ exceed the minimum standards suggested by Lubrano et al. (2003). Similarly, only 12 of 48 departments are over the corresponding minimum standards. Royuela et al. (2006) concluded that 7 out of 62 public and private Spanish Universities had never published a single article in EconLit during 1994-2003 and 11 had never appeared in the records of the SSCI. On average, a Spanish faculty member during this period published only one EconLit article every 13.5 years or one ISI article every 22 years. $^{4}$

In Villar (2003) countries are ranked in terms of a productivity indicator equal to the production index in relation to the size of the population for each country, in relation to the productivity of the UK measured in the same way. During the last third of the twentieth century only the Scandinavian countries (except Finland), Belgium and The Netherlands show productivity indices close to that of the UK. Those of the remaining nine European countries are lower than $50 \%$ of the index of the reference country. In particular, the productivity of the Spanish (or German) academic economists measured by production per capita is, approximately, five times lower than that of the UK. We have seen the rapid progress of the Spanish research production during the 1990s. Nonetheless, when the population is taken into account, at the close of the last century Spain occupies 12th place in the EU and its productivity index only reaches $25 \%$ of that of the UK. The phenomenon persists when the research output is measured

\footnotetext{
${ }^{4}$ These statistics on the shortage of economic research production in Spain are accompanied by very low success rates in the 6-year research prizes awarded by the Ministry of Education since the end of the 1980s to all applicants who meet very low minimum standards. In 2003, for example, only $53 \%$ of the applicants in economics, compared to $78 \%$ in other disciplines, were successful (see García-Ferrer et al. 2005, Table 2, as well as Royuela et al. 2006, Appendix A.1).
} 
after appropriate adjustments are made for the many issues reviewed in "A summary of alternative methodologies" section (see Ruiz-Castillo 2006a, for some evidence among the top 200 departments worldwide, and the European top 75 centers).

The conclusion is clear: wherever we look at, the distribution of scientific publications in economics at the end of the twentieth century is extremely unequal. Researchers and research centers that regularly contribute to the total volume of publications constitute a minority in their respective countries. According to all available indicators, this phenomenon is even more pronounced in Spain than in the rest of Europe. The analysis of the inequality of the distribution of research output across Spanish institutions is left for the next section.

\section{Spain}

This Section is organized around the following three issues: the identification of institutions of excellence within Spain; the evolution of their standing in an international context, and the position that the best Spanish centers occupy when research output is classified by major fields.

\section{The overall situation within Spain}

We shall begin by summarising the most significant papers regarding the recent evolution of research in Spain. Institutions in Table 6 are ranked according to Kalaitzidakis 2, a criterion limited to the top ten journals that has been rated as having a "very low" degree of egalitarianism and has been used in the ranking of the top 20 centers worldwide in Table 2. Information is also provided on the criterion used internally in the UCIII that has been rated as having a "high" degree of egalitarianism. These are two of the four criteria used in Dolado et al. (2003) for the period 1990-1999. Lastly, the ranking according to the European Commission (2004) has been included in the last column of that Table; since this methodology counts the articles in all the journals in EconLit without any adjustment for quality, it is assigned the highest degree of egalitarianism. ${ }^{5}$

Two points will be emphasized. In the first place, it is enlightening to compare the ranking of the Spanish institutions according to the two opposing criteria as far as the degree of egalitarianism is concerned: that of Kalaitzidakis 2 and that of the European Commission (2004). It can be observed that:

- UPF, UAB-IAE, and UCIII hold the first three places in both classifications. That is, whether a version of the blue ribbon journals or the gross volume of publications is taken into account, during the 1990s these three centers clearly stand out from the rest.

\footnotetext{
5 Recall that the methodology of the European Commission is the only one that adjudicates all of the publications of each researcher during the 1990s to the institution where the researcher is at the end of the period. The remainder adjudicate each publication to the institution to which the author(s) declares himself affiliated at the moment the publication in question appears.
} 
Table 6 Top research centers in Spain during the 1990s according to different methodologies, ordered according to Kalaitzidakis 2 (which takes into account the ten best journals)

\begin{tabular}{|c|c|c|c|}
\hline $\begin{array}{l}\text { No. of journals: } \\
\text { Egalitariansm: }\end{array}$ & $\begin{array}{l}\text { Kalaitzidakis } 2 \\
10 \\
\text { Very low }\end{array}$ & $\begin{array}{l}\text { UCIII } \\
281 \\
\text { High }\end{array}$ & $\begin{array}{l}\text { European Commission } \\
680 \\
\text { Maximum }\end{array}$ \\
\hline 1. UPF & & 3 & 1 \\
\hline 2. UAB-IAE & & 1 & 2 \\
\hline 3. UCIII & & 2 & 3 \\
\hline 4. UAL & & 4 & 9 \\
\hline 5. CEMFI & & 8 & 12 \\
\hline 6. Bank of Spain & & 7 & 7 \\
\hline 7. FEDEA & & 17 & 15 \\
\hline 8. U. País Vasco & & 5 & 6 \\
\hline 9. U. Salamanca & & $*$ & 19 \\
\hline 10. U. Zaragoza & & 10 & 8 \\
\hline 11. U. Complutense & & 9 & 5 \\
\hline 13. U. Valencia & & 6 & 4 \\
\hline * U. Cantabria & & 19 & 20 \\
\hline * U. Pública de Navarra & & * & 10 \\
\hline
\end{tabular}

* Situated above position 19

Source: First two columns, Dolado et al. (2003, Tables 2 and 3)

Column 3, European Commission (2004, Table A2.3, Annex II)

- There are institutions of smaller size and/or oriented to journals with greater impact, which when research output is identified with the gross volume of publications they hold positions relatively far from the top; yet when the criterion of maximum elitism is used their relative position improves considerably. This is the case of the Universities of Alicante and of Salamanca, which go from 9th and 19th positions according to the European Commission to 4th and 9th according to Kalaitzidakis 2, respectively. This happens as well to two research centers: CEMFI, created in the late 1980s under the auspices of the Bank of Spain and financed by financial system institutions for the training of professionals in the banking/finance sector, and FEDEA (Fundación de Estudios de Economía Aplicada), established in 1985 with the main aim of developing applied research. These centers go from the 12th and 15 th position to the 5 th and 7 th, respectively.

- Other institutions move in the opposite direction when the ranking methods become less egalitarian. This is the case of the University of Valencia, the Complutense of Madrid, the Pública of Navarra and, to a lesser extent, the Universities of País Vasco and Zaragoza, which hold 4th, 5th, 10th, 6th and 8th positions in column 3 of Table 6 , and the 13th, 11th, 19th, 8th and 10th, respectively, in column 1 of said Table. These are centers that are more oriented towards local journals, and/or those with less international impact. 
- Finally, the Research Department of the Bank of Spain maintains the 7th and 6th positions in the two rankings.

In the second place, taking into account all methods used in Dolado et al. (2003), as well as the results provided in Bergantiños et al. (2002), García et al. (1999a), and Royuela et al. (2006) using other methodologies, the resulting ranking is quite robust (see the details in Ruiz-Castillo 2006b; for a distinction between economics, business and econometrics departments and institutions that may include all three, see Rodriguez 2006):

- The UAB-IAE, UPF and UCIII hold the first three positions. If the most elitist criteria are followed, UPF occupies first place; otherwise, the tandem UAB-IAE is adjudicated the 1 st position.

- The UAL clearly registers 4th in the ranking, while the CEMFI is 5th.

- The Research Department of the Bank of Spain and the University of País Vasco hold the 6th and 7th positions, while the Universities of Zaragoza, Valencia and Complutense of Madrid are in the 8th to 10th positions.

The Spanish centers of excellence in the international scene

The position of the Spanish centers among the top 200 in the world and/or the top 75 in Europe during the 1990s is summarized in Table 7 in accordance with 11 methodologies or different periods of time. ${ }^{6}$ In light of the above results, it is not surprising that the Spanish centers that appear in Table 7 are confined to those situated in the first positions of the national ranking in Table 6. Since the first part of the 1990s, the presence of three Spanish institutions must be highlighted: UAB-IAE, UPF and UCIII. The UAL and CEMFI are likewise present in about half of the rankings. ${ }^{7}$ These five centers, which represent only $15 \%$ of the 34 with some publication in EconLit during 1991-2000 (see European Commission 2004, Annex II), are responsible for $40 \%$ of the gross output in the country. All of which rules out, as pointed out by Royuela et al. (2006), the existence of a trade-off between quantity and quality: the centers carrying out the greater part of quality research also distinguish themselves in gross output volume. What happens is that the publications of other Spanish centers appear for the most part in journals with less international impact. ${ }^{8}$

Notice that UAB-IAE, the oldest among the best Spanish centers, quickly achieves some prominence since the early 1990s. The UAL develops some time later, while UPF and UCIII are only established in 1990-1991. How do these four centers fare as time goes by? An answer is provided in Rows 10 and 11 in Table 7, which are comparable because they apply the same methodology to Europeans centers in 1991-1996

\footnotetext{
${ }^{6}$ Of all the methods discussed in the Appendix, only the results from Combes and Linnemer (2003) are excluded for reasons explained in Ruiz-Castillo (2006b).

${ }^{7}$ Recall that, by using the aggregate score of all members in an institution, all methods are biased against small centers such as UAL and CEMFI.

${ }^{8}$ Royuela et al. (2006), however, detect less distance between the levels of scientific production of the ten top Spanish Universities and the remainder in 1999-2003 than that which existed in 1994-1998.
} 


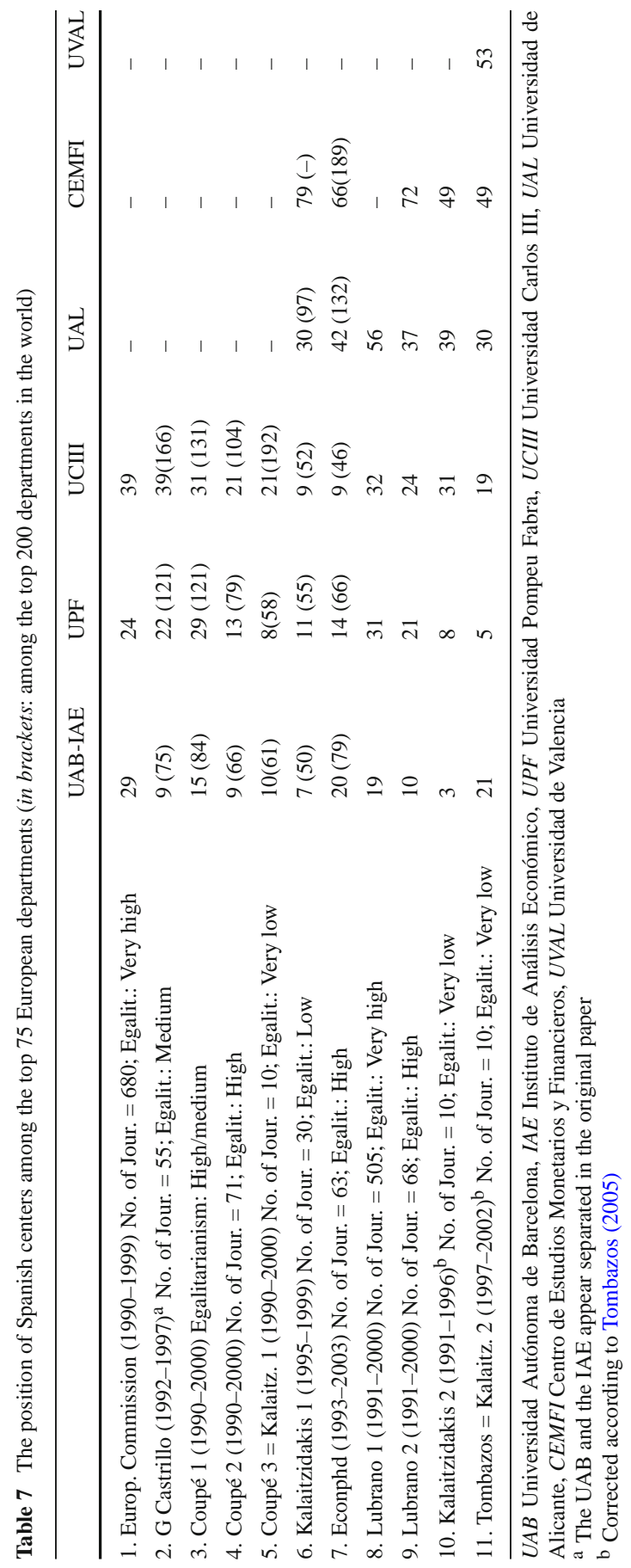


and 1997-2002, respectively: the UAB-IAE loses some ground, while the other three university departments considerably improve their positions. This has an interesting interpretation that might be applicable to other countries: newly created schools are able to change matters drastically in a short period of time (for a careful study of time spans, see Rodriguez 2006).

As far as the worldwide rankings are concerned, two fundamental features are confirmed. First, the UAB-IAE, UPF, and UCIII hold positions 120th to 160th worldwide at the beginning of the 1990s, but advance to positions near 50th to 80th at the end of that period. Furthermore, in the ranking of Econphd the UAL and the CEMFI hold positions between 130th and 140th at the end of the century. Second, as the degree of egalitarianism decreases, the positions of the Spanish centers, especially UPF, improve. This can be seen clearly upon comparing the rankings of Coupé 2 and Coupé 3 and, except for UCIII and CEMFI, those of Econphd and Kalaitzidakis 1. Taking into account that none of these four methods include local journals, it can be concluded that as greater relative weight is given to the top international journals the position of the Spanish centers in the world rankings improves at the expense of institutions from the US, Europe, and other parts of the world.

Within the European scene, if we place ourselves at the beginning of the period (García-Castrillo) and/or we simply consider the volume of articles published during the 1990s (European Commission), then the UAB-IAE, UPF and UCIII hold different rankings between the 20th and 40th best positions in Europe. Nevertheless, when the methodology used is refined (as in the three versions of Coupé and the two of Lubrano) these institutions register an immediate improvement, placing themselves between the 10th and 30th positions; moreover, the UAL also appears between 35th and 55th and the CEMFI at 72nd. Finally, when we come to more recent periods (in Kalaitzidakis 1, Econphd and Tombazos) and/or consider less egalitarian criteria (such as Kalaitzidakis 2), the first three centers achieve a position in the top 20, with some of them appearing in the top 10, while the UAL reaches the 30-40 segment and the CEMFI registers a position in the top 50.

Finally, in Table 8 the top 22 Universities are ranked according to five methods Kalaitzidakis 1, Coupé 1 and 3 (which coincides with that of Kalaitzidakis 2), Lubrano 2, and Econphd. All selected universities appear within the first 22 positions according to at least three methods. Although the clarity and the robustness of the following conclusions are inferior to that obtained in the world ambit, the available information for the 1990s can be summarized as follows:

- LSE and Tilburg hold the top two spots, while University College London, Oxford, Toulouse and Cambridge are situated in the 3rd to 6th positions.

- Amsterdam, Warwick, UPF, the Catholic University of Louvain, the UAB-IAE, Essex, Erasmus, UCIII, York, the INSEE, the Stockholm School of Economics and the Universities of Stockholm, Bonn, Vienna, Copenhagen and Southampton round out the 7 th to 22 nd positions.

That is, when we informally combine several ordinal criteria of classification, it can be concluded that eight universities of the United Kingdom, three Dutch, three Spanish, two French, two Swedish and one each from Belgium, Austria, Germany and Denmark form the top 22 of Europe during the 1990s. 
Table 8 The top 22 European departments according to different methodologies and periods of time, ordered according to Kalatzidakis 1 (which takes into account the 30 best journals)

\begin{tabular}{|c|c|c|c|c|c|}
\hline $\begin{array}{ll}\text { Kalaitzidakis } 1 & \\
\text { Period: } & 1995-1999 \\
\text { No. of Journals: } & 30 \\
\text { Egalitarianism: } & \text { Low }\end{array}$ & $\begin{array}{l}\text { Coupé 1 } \\
\text { 1990-2000 } \\
- \\
\text { Medium/high }\end{array}$ & $\begin{array}{l}\text { Coupé } 3 \\
1990-2000 \\
10 \\
\text { Very low }\end{array}$ & $\begin{array}{l}\text { Coupé } 3 \\
1997-2002 \\
10 \\
\text { Very low }\end{array}$ & $\begin{array}{l}\text { Lubrano } 2 \\
1991-2000 \\
68 \\
\text { High }\end{array}$ & $\begin{array}{l}\text { Econphd } \\
1993-2003 \\
63 \\
\text { High }\end{array}$ \\
\hline 1. Tilburg University & 5 & 12 & 7 & 1 & 3 \\
\hline 2. LSE & 1 & 1 & 1 & 2 & 1 \\
\hline 3. University College London & 4 & 3 & 3 & 12 & 10 \\
\hline 4. Cambridge University & 3 & 6 & 6 & 8 & 7 \\
\hline 5. Oxford University & 2 & 2 & 4 & 5 & 4 \\
\hline 6. Toulouse University & 11 & 4 & 2 & 4 & 2 \\
\hline 7. UAB-IAE & 15 & 10 & 21 & 10 & 20 \\
\hline 8. University of Amsterdam & 7 & 20 & 14 & 6 & 6 \\
\hline 9. UCIII & 32 & 22 & 19 & 24 & 9 \\
\hline 10. University of Essex & 12 & 15 & 17 & 11 & 11 \\
\hline 11. UPF & 30 & 8 & 5 & 21 & 14 \\
\hline 12. Catholic University of Louvain & 9 & 9 & 15 & 3 & 19 \\
\hline 13. Erasmus University & 8 & 29 & 38 & 7 & 17 \\
\hline 14. INSEE & 19 & 7 & 18 & 17 & - \\
\hline 15. Stockholm School of Economics & 20 & 19 & 11 & 14 & 16 \\
\hline 16. University of Warwick & 6 & 16 & 12 & 9 & 5 \\
\hline 17. University of Vienna & 34 & 18 & 26 & 31 & 31 \\
\hline 18. University of Bonn & 17 & 11 & 9 & 18 & 22 \\
\hline 19. University of Copenhagen & 25 & 23 & 13 & 19 & 18 \\
\hline 20. University of York & 10 & 24 & 24 & 16 & 13 \\
\hline 21. U. Southampton & 18 & 14 & 10 & 32 & 28 \\
\hline 22. Stockholm U & 13 & 5 & 8 & 13 & 12 \\
\hline 23. Free University of Brussels & 27 & 13 & 23 & 20 & 43 \\
\hline 25. Université Paris I & 23 & 21 & 25 & 25 & 26 \\
\hline 37. Birbeck College & 21 & 17 & 48 & 33 & 36 \\
\hline 38. London Business School & 14 & 26 & 52 & 26 & 34 \\
\hline 42. U. Zurich & 42 & 20 & 16 & - & 30 \\
\hline 43. University of Nottingham & 16 & 30 & 46 & 27 & 15 \\
\hline 49. European Institute of Florence & 28 & 31 & 28 & 44 & 8 \\
\hline 51. DELTA & - & - & 20 & 22 & 62 \\
\hline
\end{tabular}

\section{The rankings by major fields}

The best paper studying areas of specialization is Econphd (2004), which covers the top universities in the world during 1993-2003, and distinguishes among six fields 
that are described in Table 9. ${ }^{9}$ The first three fields-Microeconomic Theory, Macroeconomics and Econometrics - refer to the most basic aspects of Economics, while the remaining three-Public Economics, Industrial Organization and Labor Economics and related areas - are applied economics fields. It is important to emphasize that the 6 areas account for $85 \%$ or more of the output of the 4 major Spanish economics institutions in Table 9. With regard to distribution by areas, the three following facts must be highlighted. First, an important percentage of the research output of these four centers is devoted to Microeconomic Theory. Second, approximately one third of the output of UCIII, UPF and the UAB-IAE is dedicated to Econometrics, Macroeconomics and Public Economics, respectively. Third, the research production of UPF, the UAB-IAE and the UAL are concentrated, relatively speaking, in 2 or 3 areas; on the other hand, UCIII devotes a reduced percentage to Macroeconomics but registers respectable percentages in the rest of the areas.

The next question is how to translate this distribution of output of the Spanish centers into the European context. The information in this respect is found in Table 10, where it can be observed that:

- UCIII holds the second European position in Econometrics (and the 10th worldwide) and, furthermore, holds the 8th position in Europe in Public Economics and in Industrial Organization, 10th in Microeconomic Theory, and 13th in Labor and Demography. ${ }^{10}$

- The UAB-IAE occupies the second position in Public Economics (and 14th in the world).

- UPF achieves 6th position, not only in Macroeconomics (where it holds the 24th position worldwide), but also in Microeconomic Theory (where it places 34th worldwide).

- In this last area, the University of País Vasco joins the top 4 Spanish institutions within the top 30 of Europe (or the top 83 worldwide).

In summary, as could be expected given the high level reached in economics in general, in some specific areas the best Spanish universities hold distinguished positions in Europe, and even in the world, and very noteworthy positions in the rest.

\footnotetext{
${ }^{9}$ Bear in mind that this methodology is characterized by 4 traits: (i) It ranks institutions according to their stock of publications in 2003. (ii) Any meaningful study by areas must use more than the 10 or 30 journals considered, for example, by Kalaitzidakis 1 and 2, respectively. Thus, Econphd includes 63 journals (listed in the Appendix). (iii) The methodology in Econphd is rated in Table 11 as having a "high" degree of egalitarianism. (iv) The top Spanish centers are very highly placed in this rating: UCIII holds the 9th and 46th positions in Europe and in the world, respectively, UPF the 14th and 66th, the UAB-IAE 20th and 79th, and the UAL 42nd and 132nd. For further evidence regarding fields from the European Commission (2004), see Ruiz-Castillo (2006a).

${ }^{10}$ It is worthwhile pointing out the two reasons that explain the good classification of UCIII in Econphd (2004). In the first place, the output of this center is relatively spread out among various areas. Thus when the number of quality journals included goes up from 10 to 30 or 63, as in Econphd, its relative position considerably improves. Secondly, Econphd is based on Kalaitrzidakis et al. (2003) where the relative situation of some key theoretical and applied Econometrics journals within the top 30 is more favorable than in the remaining institutions. Econometrics, of course, is the area in which UCIII particularly stands out.
} 
Table 9 Percentage distribution of scientific production by broad fields in the 1993-2003 period in the best Spanish departments according to Econphd (2004)

\begin{tabular}{lrccr}
\hline & UCIII & UPF & UAB-IAE & UAL \\
\hline 1. Microeconomic theory & 19.6 & 28.2 & 24.5 & 38.3 \\
2. Macroeconomics & 8.5 & 33.7 & 9.4 & 9.7 \\
3. Econometrics & 31.9 & 10.2 & - & 10.7 \\
4. Public economics & 12.3 & 6.1 & 33.2 & 21.9 \\
5. Industrial organization & 10.4 & 8.6 & 10.7 & - \\
6. Labor economics & 12.7 & - & 7.2 & 11.3 \\
7. Other fields & 4.6 & 13.2 & 15.0 & 7.9 \\
8. Total & 100.0 & 100.0 & 100.0 & 100.0 \\
\hline
\end{tabular}

Note: The two digit categories of the Journal of Economic Literature are in parenthesis

1. Mathematical Methods and Programming (C6); Game Theory and Bargaining Theory (C7); Experiment Design (C9); General Equilibrium and Disequilibrium (D5); Information, Knowledge and Uncertainty (D8)

2. Interterm Choice and Economic Growth (D9); General Aggregate Models (E1); Consumption, Saving, Production, Employment and Investment (E2); Prices and Cycles (E3); Money and Interest Rates (E4); Monetary Policy, Central Banking and Money and Credit Supply (E5); Macroeconomic Policy Training, Macroeconomic aspects of Public Finance and Macroeconomic Policy (E6); International Finance (F3); Macroeconomic aspects of Trade and International Finance (F4); Public Spending (H5); Budget, Deficit and Public Debt (H6); Local and State Governments (H7); Other Topics (H8)

3. Statistic and Econometric Methods: General Aspects (C1); Econometric Methods: Single Equation Models (C2); Econometric Methods: Simultaneous Equation Models (C3); Econometric Methods: Special Topics (C4); Econometric Modelling (C5); Data Gathering and Estimation Methods (C8)

4. Welfare Economics (D6); Collective Decision Making (D7); Structure and Size of the Public Sector (H1); Taxes, Subsidies and Income (H2); Fiscal Policy and Behavior of Market Agents (H3); Goods Provided by the Public Sector (H4); Basic Areas of Law (K1); Regulation and Commercial Law (K2): Other Substantive Areas of Law (K3); Legal Procedures and Systems and Illegal Behavior (K4)

5. Market Structure, Entrepreneurial Strategy and Market performance (L1); Objectives, Organization and Behavior of the Company (L2); Non-profit Organizations and Public Companies (L3); Policy of Defence of Competition (L4); Industrial Policy and Regulation (L5); Industrial Studies: Industry (L6), Primary Products and Construction (L7), Services (L8), Transport and Utilities (L9); Production and Organization (D2); Business Administration (M1); Technological Changes (O3)

6. Economic Demographics (J1); Time Allotment, Work and Job Determination (J2); Salaries, Compensations and Labor Costs (J3); Specific Labor Markets (J4); Labor Relations, Unions and Collective Bargaining (J5); Mobility, Unemployment and Job Vacancy (J6); Discrimination (J7); Work Standards (J8); Household Economy and Family Economy (D1); Distribution (D30); Health (I1); Education (I2); Cultural Economy (Z1)

\section{Conclusions}

This paper has reviewed the literature regarding the rankings of the centers of excellence in economics according to articles published in academic journals that use an anonymous evaluation procedure. The main objective has been to place the research carried out in Spain during the 1990s within an international perspective.

Existing methodologies for weighting journals according to quality combine in different degrees objective information from the citations that the journals receive with the subjective information that experts provide. Since there exists no generally 
Table 10 The place held by Spanish departments by broad fields in 1993-2003 in relation to the best European centers according to Econphd (2004)

\begin{tabular}{|c|c|c|c|c|c|}
\hline \multicolumn{2}{|l|}{ Microeconomics } & \multicolumn{2}{|l|}{ Macroeconomics } & \multicolumn{2}{|l|}{ Econometrics } \\
\hline 1. Tilburg U. & $(11)$ & 1. LSE & $(12)$ & 1. LSE & (2) \\
\hline 2. U. Toulouse & (16) & 2. European institute & (14) & 2. UCIII & (10) \\
\hline 3. cole Nat. Ponts and Chaussees & $(22)$ & 3. U. Warwick & $(15)$ & 3. European institute & (14) \\
\hline 4. LSE & (24) & 4. Tilburg U. & $(21)$ & 4. U. Amsterdam & $(15)$ \\
\hline 5. UCL & $(30)$ & 5. U. Amsterdam & $(22)$ & 5. Erasmus U. & (23) \\
\hline 6. UPF & $(34)$ & 6. UPF & $(24)$ & 6. U. Cambridge & $(29)$ \\
\hline 7. U. Essex & (35) & 7. U. Copenhagen & (28) & 7. U. Oxford & (31) \\
\hline 8. U. Paris I & $(36)$ & 8. Stockholm U. & $(30)$ & 8. U. York & $(32)$ \\
\hline 9. U. Bonn & (35) & 9. U. Cambridge & $(39)$ & 9. U. Helsinki & $(35)$ \\
\hline 10. UCIII & $(41)$ & 10. Birbeck College & $(44)$ & 10. Tilburg U. & $(42)$ \\
\hline 13. UAB & $(51)$ & 28. UCIII & $(90)$ & 25. UPF & (77) \\
\hline 22. UAL & $(66)$ & 44. UAB & $(120)$ & 26. CEMFI & (78) \\
\hline 29. U. País Vasco & $(83)$ & 76. UAL & (201) & 54. UAL & (139) \\
\hline \multicolumn{2}{|l|}{ Public economics } & \multicolumn{2}{|l|}{ Industrial organization } & \multicolumn{2}{|l|}{ Labor economics } \\
\hline 1. U. Toulouse & (6) & 1. U. Toulouse & (5) & 1. LSE & (13) \\
\hline 2. UAB & (14) & 2. U. Oxford & (10) & 2. U. Essex & (14) \\
\hline 3. LSE & (15) & 3. LSE & $(17)$ & 3. UCL & (20) \\
\hline 4. U. Amsterdam & (24) & 4. UCL & $(31)$ & 4. U. Warwick & $(25)$ \\
\hline 5. Tilburg U. & $(25)$ & 5. U. C. Louvaine & $(38)$ & 5. U. Oxford & (28) \\
\hline 6. U. Warwick & (26) & 6. U. Warwick & $(41)$ & 6. Tilburg U. & (29) \\
\hline 7. Stockholm U. & (29) & 7. U. Cambridge & (43) & 7. Free U. Amsterdam & $(38)$ \\
\hline 8. UCIII & (33) & 8. UCIII & $(50)$ & 8. Stockholm U. & $(41)$ \\
\hline 9. U. Bonn & $(42)$ & 9. K. U. Leuven & $(51)$ & 9. Uppsala U. & $(42)$ \\
\hline 10. U. Zurich & $(47)$ & 10. U. Bonn & $(53)$ & 10. U. Amsterdam & $(43)$ \\
\hline 16. UAL & $(51)$ & 27. UAB & $(83)$ & 13. UCIII & $(50)$ \\
\hline 32. UPF & (66) & 29. UPF & $(88)$ & 38. UAB & $(139)$ \\
\hline & & & & 50. UAL & $(163)$ \\
\hline
\end{tabular}

World rankings are in parenthesis

accepted, fully satisfactory system of journal weightings, it is necessary to compare the results obtained from several alternative methods. To facilitate this task, the different methodologies have been classified according to their degree of egalitarianism. A methodology is more egalitarian the greater the weight assigned to local journals and the smaller the weight assigned to the top journals relative to the remaining journals with some international impact.

As was mentioned in the Introduction, the most important conclusions regarding economics research in the international sphere can be summarized as follows.

1. At the end of the twentieth century, world scientific production is still dominated by the US. Moreover, the more stringent the criteria of excellence used in the 
comparison, the wider the gap becomes (see Tables 1, 2, 3, 4). In the words of highly qualified professional leaders, "The studies thus paint a well-known but distressing picture of relatively inferior performance in Europe, reflecting the poor governance of most European universities and the limited role given to research criteria in their funding" (Neary et al. 2003, p. 1248).

2. Although some European countries grew very quickly during the 1990s, among which Spain and The Netherlands stand out, the UK maintains its predominance in Europe (see Table 5). Spain ends up the twentieth century in fifth or sixth place in Europe for volume of publications according to EconLit or the ISI, respectively.

3. As in all the sciences, the distribution of scientific publications is very unequal regardless of the geographical area being investigated. This phenomenon is even more pronounced in Spain: the significant growth of Spanish publications in the databases of the ISI and EconLit is a result of the activity of a small percentage of researchers in a reduced number of institutions.

4. Beyond the mere volume of research papers, when the quality of the journals in which they appear and other adjustment factors are taken into account, only five Spanish centers appear regularly in the international rankings. What is truly extraordinary are the achievements accomplished by the group composed of the UAB-IAE, UPF, and UCIII, together with the UAL and CEMFI (see Tables 7, 8, 10). The bottom line is that, in the year 2000, Spain leaps up to the fourth position in Europe and the seventh worldwide as a producer of research of excellence measured by journal pages adjusted by quality and other factors.

Drèze and Estevan (2007) contains an enlightening and provocative discussion of the policy implications in a European context of points 1-3. Here we will restrict ourselves to the Spanish situation, which has been aptly summarized as "a substantial process of improvement, accompanied by a notable polarization" (Villar 2003, p. 99). In the remaining pages we briefly inquire into the factors that might explain this phenomenon. While this is not the place for an in-depth analysis, the elements that distinguish the more productive Spanish universities from the rest are not difficult to determine.

Let us begin by recalling the important investment in human capital, which, from 1970 until today, has led more than one hundred Spanish economists to obtain their doctoral degrees in some of the top universities in the US and the UK. These are what the sociologist Pérez-Díaz (2005) calls the "cultural hybrids (natives socialized in a foreign setting)". Although some of the best reside outside of Spain, the majority of the beneficiaries of this training carry out their work in a large variety of Spanish organizations. The novelty lies in that they are the ones that have provided the impetus for a radical change of course in the Spanish universities that stand out at the international level. The economics departments within the recently established universities, such as UPF and UCIII, as well as in older ones which are research oriented, such as the UAB and the UAL, are dedicated first and foremost to fomenting quality research.

The hiring policy in these institutions has been structured along three key elements. First, by avoiding the hiring of graduates from their own doctoral programs, the traditional endogamy characterizing the Spanish university system has been abolished. 
The recruitment of new faculty is carried out by means of a rigorous selection system open to interested candidates from any other university. (The steps include: advertising job vacancies on the Internet; first round candidate selection by an ad hoc committee; interviews with those selected during international conferences; Seminar presentation and, upon hearing department members' opinions, extension of work offers.) Second, the academic staff hired in this way, whose performance is evaluated every two years, have a maximum period of 6 years to become tenured faculty members. The minimum standards for research and teaching excellence to achieve this status, as well as for further advance in the academic career, are clearly established beforehand. The decisions regarding promotion are adopted by a department vote after the discussion of a written proposal by an ad hoc committee that takes various factors into account (such as the quantity and the quality of work done, the candidate's research proposal, and letters of references from outside experts). Third, there are diverse internal systems of incentives to complement the civil servant salary and/or to assign the teaching load. These systems, which are contingent on the research (and teaching) trajectory of each faculty member, are based on methods for weighting academic journals similar to those reviewed in this paper.

Although the earnings of the Spanish teaching and research staff have slightly decreased in real terms in the past 15 years, the increase in public resources for research from regular university budgets and through competitive selection processes in Spain and in Europe has been advantageous for the universities with which we are concerned here in two ways: (i) in financing travel expenditures, computer facilities, sabbaticals or stays of visiting foreign faculty, and (ii) as a funding source for Spanish and foreign students in international doctoral programs that are conducted in English.

Lastly, the international context cannot be overlooked. With the exception of the UK, the rest of the European university economics departments are organized in markets that are relatively closed to the outside and dominated by national traditions where research does not necessarily hold a predominant place (see, for example, Portes 1987, and Frey and Eichenberger 1993). So, the combination of a rigorous merit system - that is innovative and attractive in the European context with the availability of resources to fund certain strategic needs, is what has made possible the expansion of the human capital already in existence in this group of 4 Spanish universities at the beginning of the 1990s with professionals from different parts of the world: approximately one fourth of the faculty members in these 4 universities are foreign. If to this we add the contribution of research centers, such as the IAE, CEMFI and FEDEA, focusing exclusively on quality research, we can understand how this reduced group of Spanish institutions has been able in record time to catapult economics research up to the levels reached by other scientific disciplines in Spain with an important international tradition. According to the electronic publication Essential Science Indicators, professional publications in Economics and Business in Spain during 2001-2005 represent 3.17\% of the world total, very near to the Spanish average for 21 sciences. In particular, 8 disciplines are ahead of Economics - Space Sciences, Agrarian Sciences, Mathematics, Microbiology, Chemistry, Animal and Vegetal Biology, Ecology and Environmental Sciences and Physics_-but the remaining 12 are below-Biology and Biochemistry, Pharmacology, Material Sciences, Neurosciences and Behavioral Sciences, Molec- 
ular Biology, Computer Sciences, Immunology, Geosciences, Engineering, Clinical Medicine, Psychology and Psychiatry, and the rest of the Social Sciences.

To conclude, we may ponder as to the soundness of this project, and the possibilities of staying at the levels reached or of taking advantage of the opportunities to decisively influence, at least in some areas, the future of European and worldwide research. We should not fool ourselves. The results reviewed in this paper are the consequence of favorable circumstances. Ceteris paribus, when the rest of the European countries loosen the reins, establish a higher level of competition in their university systems and design their incentive systems so as to foment quality research, with the current real salaries in Spain it will be difficult for the most prestigious Spanish institutions to maintain their current attractiveness.

On the other hand, once demonstrated that it is possible to compete in the world context from Spain, the increase of resources for boosting existing incentives and remunerating top researchers at the level demanded by the international market could constitute an interesting alternative within Spanish society. As in the US, whose performance we wish to emulate, in order to put this option into practice it would be necessary to draw on new resources, not only from the public university system, but from private firms, private foundations, alumni, and private donors.

\section{Methodological appendix}

This Appendix briefly discusses the more controversial aspects of the available methods for ranking research institutions in economics: the bias against small centers, and the determination of weights $w_{j}=w\left(P_{i}\right)$ for all $P_{i}$ in journal $j$ (for a more thorough review of these issues, see Ruiz-Castillo 2006a).

First, as pointed out in "A summary of alternative methodologies" section, the aggregate score for all members of an institution measures its global strength but favors the larger departments. An alternative is to classify each institution according to its per capita score that can be seen as a (crude) measure of productivity. Given the great inequality in the distribution of individual publications within each center, the per capita score is not as attractive as an indicator of the research activity of the institution as a whole. In any case, the most serious problem with this approach is that the size of an institution at a given moment in time is not easy data to obtain. In these circumstances, it is tempting to identify size with the number of active researchers who have at least one publication, a method that favors those institutions whose publications are due to a small number of authors. The comparability of any indicator by size is complicated in still two other ways. First, there are centers exclusively dedicated to research where the large majority of their members publish regularly; on the other hand, in university departments the rule is that a certain number of people are dedicated almost exclusively to teaching and other managerial tasks and, to a certain extent, have given up research work. Second, there are universities where researchers in Applied Economics, Business Economics or Econometrics are integrated in a single Economics Department - as in UPF - whereas in others this is not the case. At any rate, except for Combes and Linnemer (2003), the rest of the studies provide 
only the total score of each center independently of its size. Therefore, this will be the classification criterion used in this paper.

Second, as also indicated in the text, there are two alternatives for determining the quality of journals. In the first place, one can use objective criteria based on the number of times an article is cited. The first limitation of this approach is that it can only be applied to the databases that have information on citations, that is, the databases produced by the ISI. In fact, most users only consider the approximately 150 academic journals that appear in the Economics section of the SSCI, excluding other relevant journals found in other thematic areas of the SSCI, as well as the SCI (Science Citation Index) for the natural sciences.

The next problem is how to use the citations to construct a weighting system for a given set of journals. The careless use of impact factors published in the JCR (Journal Citation Reports) of the SSCI for measuring the influence or quality of a journal has been widely criticized (see, for example, Moed and van Leeuwen 1996; Moed 2002; Amin and Mabe 2000). Among economists, impact factors are questioned in Lubrano et al. (2003), and García-Ferrer et al. (2005). One of the most obvious problems is the variability of impact factors over time. To alleviate this, García-Castrillo et al. (2002) select 55 journals with the greatest average of the impact factors during the 6-year period 1992-1997. Given the exclusion of local journals and the large difference between the impact factors of the most cited journals and the rest, this methodology is assigned a "low" degree of egalitarianism.

Following Liebowitz and Palmer (1984), other authors recognize that citations should receive different weights depending on the prestige of the journal they come from. Among them, Kalaitzidakis et al. (2003) eliminate self-citations, namely, the citations of the articles in a journal that come from other articles in this same journal, and select the top 30 journals that happen to receive $83.4 \%$ of the total number of citations adjusted for different concepts. ${ }^{11}$ According to Combes and Linnemer (2003, p. 1259), the articles in these 30 journals represent $13.8 \%$ of the total in EconLit. Furthermore, of the 22,000 economists appearing in EconLit from 1971-2000, more than $85 \%$ have never published in any of the 30 journals in question. This methodology, which will be referred to as Kalaitzidakis 1 (to distinguish it from other proposals by these authors that will be reviewed below), is classified as having a "low" degree of egalitarianism.

Econphd (2004) looks at 63 journals, whose citations represent $95.6 \%$ of the total number of citations adjusted for all concepts in Kalaitzidakis et al. (2003). These are the first 64 journals from the list of Kalaitzadikis et al. (2003), once having eliminated

\footnotetext{
11 These journals are: American Economic Review, Journal of Political Economy, Econometrica, Quarterly Journal of Economics, Journal of Econometrics, Journal of Economic Perspectives, Journal of Economic Theory, Journal of Monetary Economics, Review of Economic Studies, Review of Economics and Statistics, Economic Journal, European Economic Journal, Games and Economic Behavior, Journal of Business and Economic Statistics, Journal of Public Economics, Journal of Human Resources, Journal of Economic Literature, Econometric Theory, Journal of Labor Economics, International Economic Review, Economic Theory, Journal of Environmental Economics and Management, Rand Journal of Economics, Journal of Financial Economics, Economics Letters, Journal of Applied Econometrics, Oxford Bulletin of Economics and Statistics, Scandinavian Journal of Economics, Journal of Economics Dynamics and Control, and Journal of International Economics.
} 
the one that appears in 41st place, the IMF Staff Papers. ${ }^{12}$ However, this method takes the logarithm of the weightings in that paper, a procedure that greatly reduces the difference between the weightings of the best journals and the rest. Therefore, although the number of journals considered is relatively small and local journals are totally excluded, Econphd is classified as having a "high" degree of egalitarianism.

The second criterion for evaluating the quality of journals is their ranking by experts. Thus, for example, in a very influential study, Kalaitzidakis et al. (1999) take as starting point the ten journals that occupy top places in Laband and Piette (1994, Table A2). The Journal of Financial Economics, the Journal of Finance and the Rand Journal of Economics, which occupy 2nd, 8th and 10th place respectively, are eliminated and substituted by the Review of Economics and Statistics, the Economic Journal and the European Economic Review, occupying the 23rd, 25th and 50th positions, respectively. The ten journals eventually selected represent 42.6 and $44.9 \%$ of the total of citations adjusted for all concepts in Laband and Piette (1984, Table A2) and Kalaitzidakis et al. (2003, Table 1), respectively. This certainly is an elitist criterion that is classified as having a "very low" degree of egalitarianism and will be referred to as Kalitzidakis $2 .^{13}$

At the other extreme, Combes and Linnemer (2003) classify the 680 EconLit journals into 6 groups that contain 5 journals with 10 points; 16 with $6.7 ; 39$ with $5 ; 68$ with $3.3 ; 138$ with 1.7 and the rest with 0.8 points. This methodology is an example where there is not much difference between the best journals and the rest, and in which local journals receive a positive score; for this reason, it is classified as having a "very high" degree of egalitarianism.

Lubrano et al. (2003) followed a mixed strategy: they started by entrusting to one of their members, Alan Kirman, the ranking of 505 journals that come from the 680 journals in EconLit after eliminating those with fewer than ten articles in 10 years. In a second phase, they gathered information on the number of citations which 307 journals receive. Finally, they asked Professor Kirman to modify his original ranking in light of this information. The result is a grouping of all the journals in 6 classes that contain 6 journals with 10 points, 17 with 8 (except for one with 7), 45 with 6 , and the remaining 437 with 4,2 , or 1 point. This is another case of "very high" egalitarianism,

\footnotetext{
12 The additional 33 journals over those of Kalitzidakis 1 are the following: Journal of Mathematical Economics, Journal of Economic Behavior and Organization, Social Choice and Welfare, American Journal of Agricultural Economics, International Journal of Game Theory, Economic Inquiry, World Bank Economic Review, Journal of Risk and Uncertainty, Journal of Development Economics, Land Economics, Canadian Journal of Economics, Public Choice, Theory and Decision, Economica, Journal of Urban Economics, International Journal of Industrial Organization, Journal of Law and Economic Organization, Journal of Law and Economics, National Tax Journal, Journal of Industrial Economics, Journal of Economic History, Oxford Economic Papers, Journal of Comparative Economics, World Development, Southern Economic Journal, Explorations in Economic History, Economic Record, Journal of Banking and Finance, Contemporary Economic Policy, Journal of Population Economics, Journal of Financial Quantitative Analysis, Journal of Institutional Theoretical Economics and Applied Economics.

13 It seems that Kalaitzidakis et al. (1999) made a mistake in establishing the journal weightings. The journals with the weightings revised by Tombazos (2005) are the following: American Economic Review (10), Econometrica (6.26), Journal of Political Economy (5.2), Quarterly Journal of Economics (4.05), Journal of Monetary Economics (4.15), Journal of Economic Theory (3.24), Review of Economic Studies (4.06), Review of Economics and Statistics (1.95), Economic Journal (0.99) and European Economic Review (0.26).
} 
which will be referred to as Lubrano 1. On the other hand, Lubrano et al. (2003) select the 68 journals with 6 or more points in an option, referred to as Lubrano 2, which is rated as having a "high" degree of egalitarianism. In the same vein, we should mention the criterion in Dolado et al. (2003) that has been used internally in the Universidad Carlos III and whose results will be reviewed below. It classifies many of the EconLit journals and other local ones into 8 categories: 3 journals receive 30 points; 11 receive 20 points; 35 receive 15 points; 40 receive 8 points; the 44 top local journals receive 4 points, while those of a second or third tier receive 2 and 1 points, respectively; finally, other Spanish journals without external evaluation receive 0.5 points. This criterion, which has been recently revised in an elitist direction, should be rated as having a "high" degree of egalitarianism.

Coupé (2003) opts for a ranking of journals based on the mean rank that they obtain according to 11 different criteria that vary from the most elite to the most egalitarian. This methodology, which will be referred to as Coupé 1, is assigned a "medium/high" degree of egalitarianism. Two other alternatives will also be used: Coupé 2, which takes into account the 71 journals included in the ranking by Laband and Piette (1994) and is rated with a "high" degree of egalitarianism; and Coupé 3, which considers the ten journals in Kalaitzidakis 2. Finally, the criterion used by the European Commission (2004) simply scores the number of publications in EconLit without making any adjustments for the differences in quality of the journals in which they appear. Because it includes all local journals and weights all types of journals equally, this criterion is characterized by a "maximum" degree of egalitarianism.

Table 11 provides a schematic comparison of the studies used in this paper-distinguishing between those who take a flow or a stock option-in terms of the treatment of publication length, co-authorship, and the factors influencing the degree of egalitarianism.

To shed some light on the reasoning that has led to the rating on egalitarianism, some additional information is offered below on the weight that three important methods assign to certain international journals in relation to the very best ones. Naturally, the reader interested in judging the differences between the different methods for him/herself should directly consult the original papers and the ample information they provide in defense of their respective approach.

\section{Weightings That the "Best" Journals Receive In Relation To Other Journals With an International Impact According To Three Different Studies}

(I) Lubrano et al. (2003) distinguish between two options according to whether the number of journals is 65 or 505. Degree of egalitarianism: High or Very high, respectively. In both cases we have:

- Any two articles in the following journals, for example, receive 12 points, more than the ten points assigned to the 6 best (American Economic Review, Econometrica, Journal of Economic Theory, Journal of Political Economy, Quarterly Journal of Economics and Review of Economic Studies) 
Table 11 Schematic comparison of the studies under review

\begin{tabular}{|c|c|c|c|c|c|c|c|}
\hline & \multirow[b]{2}{*}{$\begin{array}{l}\text { Publication } \\
\text { length: } \beta(\mathrm{p})\end{array}$} & \multirow[b]{2}{*}{$\begin{array}{l}\text { Co-author } \\
\alpha(\mathrm{p})\end{array}$} & \multicolumn{5}{|c|}{ Journal weights: $\mathrm{w}(\mathrm{P})$} \\
\hline & & & $\begin{array}{l}\text { Objective/ } \\
\text { subjective }\end{array}$ & $\begin{array}{l}\text { No of } \\
\text { journals }\end{array}$ & $\begin{array}{l}\text { Distance } \\
\text { best/rest }\end{array}$ & $\begin{array}{l}\text { Local } \\
\text { journals }\end{array}$ & $\begin{array}{l}\text { Degree of } \\
\text { egalitarianism }\end{array}$ \\
\hline \multicolumn{8}{|l|}{ Flow } \\
\hline $\begin{array}{l}1 \text { Lubrano } 1 \\
(1990-2000)\end{array}$ & $\beta(\mathrm{p})=1$ & $\mathrm{n}^{1 / 2}$ & Both & 505 & Small & Yes & Very high \\
\hline $\begin{array}{l}2 \text { Lubrano } 2 \\
(1990-2000)\end{array}$ & $\beta(\mathrm{p})=1$ & $\mathrm{n}^{1 / 2}$ & Both & 68 & Small & No & High \\
\hline $\begin{array}{l}3 \text { Coupé } 2 \\
(1990-2000)\end{array}$ & No of pages ${ }^{b}$ & $\mathrm{n}$ & Objective & 71 & Medium & No & High \\
\hline $\begin{array}{l}4 \text { Coupé } 1 \\
\quad(1990-2000)\end{array}$ & - & - & - & - & - & - & Medium/high \\
\hline $\begin{array}{l}5 \text { G Castrillo } \\
(1992-1997)\end{array}$ & No of pages & $\mathrm{n}$ & Objective & 55 & Large & No & Medium \\
\hline $\begin{array}{c}6 \text { Kalaitzidakis } 1 \\
(1995-1999)\end{array}$ & No of pages ${ }^{b}$ & $\mathrm{n}$ & Objective & 30 & Large & No & Low \\
\hline $\begin{array}{l}7 \text { Kalaitzidakis } 2 \\
(1991-1996, \\
1997-2002)=\text { Coupé } 3 \\
(1990-2000)\end{array}$ & No of pages & $\mathrm{n}$ & Subjective & 10 & Large & No & Very Low \\
\hline \multicolumn{8}{|l|}{ Stock } \\
\hline $\begin{array}{l}8 \text { European Commission } \\
(1990-1999)\end{array}$ & $\beta(\mathrm{p})=1$ & $\alpha(\mathrm{p})=1$ & Objective & 680 & Small & Yes & Maximum \\
\hline $\begin{array}{l}9 \text { Combes and Linnemer }{ }^{\mathrm{a}} \\
(1996-2000)\end{array}$ & No of pages & $\mathrm{n}$ & Subjective & 680 & Small & Yes & Very high \\
\hline $\begin{array}{l}10 \text { Econphd } \\
(1993-2003)\end{array}$ & No of pages ${ }^{b}$ & $\mathrm{n}$ & Objective & 63 & Small & No & High \\
\hline
\end{tabular}

a The results from Combes and Linnemer (2003) are excluded in the text for reasons explained in RuizCastillo (2006b)

${ }^{\mathrm{b}}$ Corrected by page size

$\begin{array}{ll}\text { Brookings Papers on Economic Activity } & \begin{array}{l}\text { Journal of Economic Dynamics and } \\ \text { Control }\end{array} \\ \text { Economica } & \text { Journal of Economic Growth } \\ \text { Economic Theory } & \text { Journal of Health Economics } \\ \text { Economics Letters } & \text { National Tax Journal } \\ \text { Economic Journal } & \text { Oxford Economic Bulletin } \\ \text { European Economic Review } & \text { Regional Science and Urban Econom- } \\ & \text { ics } \\ \text { Demography } & \text { Social Choice and Welfare }\end{array}$

- Ten articles in any local journals, such as Investigaciones Económicas, Spanish Economic Review, Economía Aplicada or Hacienda Pública Española, are equivalent to one journal among the 6 best. 
(II) Econphd (2004) considers 63 journals. Degree of egalitarianism: high

- Any two articles in the following journals receive the approximate number of points assigned to American Economic Review or Econometrica:

Economic Journal

Economic Theory

Economics Letters

European Economic Review

International Economic Review
Journal of Human Resources

Journal of Economic Literature

Journal of Labor Economics

Journal of Public Economics

Oxford Bulletin of Economics and

Statistics

Journal of Economic Dynamics and Rand

Control

Journal of Environmental Economics Scandinavian Journal of Economics

(III) Kalaitzidakis 1 considers 30 journals. Degree of egalitarianism: low.

- Any set of 4/5 articles in the following journals receives the approximate number of points assigned to American Economic Review or Econometrica
Economic Journal
Economics Letters
International Economic Review
Economic Theory
Journal of Human Resources
European Economic Review
Journal of Economic Literature
Journal of Public Economics

- The sum of one article in each of the following nine journals is approximately equivalent to the points assigned to American Economic Review or Econometrica:

\author{
Journal of Applied Econometrics \\ Journal of Economic Dynamics and \\ Control \\ Journal of Environmental Economics \\ Rand \\ Journal of Financial Economics \\ Journal of International Economics
}

Journal of Labor Economics

Oxford Bulletin of Economics and Statistics

Journal of Economics

Scandinavian Journal of Economics

\section{References}

Amin M, Mabe M (2000) Impact factors: use and abuse. Perspect Publish 1:1-16

Bergantiños G, Da Rocha JM, Polomé P (2002) La investigación española en economía, 1995-99. Investigac Econ XXXVI:373-392

Combes P, Linnemer L (2002) Measuring and ranking economics throughout Europe: a complete report. http://www.enpc.fr/ceras/combes/pdf/Combes_Linnemer_Europe_07_2003_part_II.pdf

Combes P, Linnemer L (2003) Where are the economists who publish? publication concentration and rankings in Europe based on cumulative publications. J Eur Econ Assoc 1:1250-1308

Coupé T (2003) Revealed performances: worldwide ranking of economists and economic departments. J Eur Econ Assoc 1:1309-1345

Dolado JJ, García-Romero A, Zamarro G (2003) Publishing performance in economics: Spanish rankings (1990-1999). Spanish Econ Rev 5:85-100

Drèze J, Estevan F (2007) Research and higher education in economics: can we deliver the Lisbon objectives? J Eur Econ Assoc 5:271-304

Dusansky R, Vernon C (1998) Rankings of U.S. economic departments. J Econ Perspect 12:157-170

Econphd (2004) Rankings. http://www.econphd.net/ 
European Commission (2004) Mapping of excellence in economics, directorate-general for research, EUR 20889

Frey B, Eichenberger R (1993) American and European economics and economists. J Econ Perspect 7:185-193

García P, Lafuente A, Montañés A, Sanz F (1999a) Producción científica en economía según publicaciones en revistas internacionales. Papele Econ Española 81:49-57

García P, Montañés A, Sanz F (1999b) La investigación en economía en España: mercado nacional versus Mercado internacional. Rev Econ Aplic VII:167-187

García-Castrillo P, Montañés A, Sanz-Gracia F (2002) A worldwide assessment of scientific production in economics (1992-1997). Appl Econ 34:1453-1475

García-Ferrer A, Poncela P, Carmona S (2005) From zero to infinity: the use of impact factors in the evaluation of economic research in Spain. Instituto de Empresa Business School Working Paper No. WP05-22

Griliches Z, Einav L (1998) Ranking economic departments. J Econ Perspect 12:233-235

Hirsh B, Austin R, Brooks J, Moore B (1984) Economics departamental rankings: comment. Am Econ Rev 74:822-826

Kalaitzidakis P, Mamuneas T, Stengos T (1999) European economics: an analysis based on publications in the core journals. Eur Econ Rev 43:1150-1168

Kalaitzidakis P, Mamuneas T, Stengos T (2003) Rankings of academic journals and institutions in economics. J Eur Econ Assoc 1:1346-1366

Kirman A, Dahl A (1994) Economic research in Europe. Eur Econ Rev 38:505-522

Laband D, Piette M (1994) The relative impact of economics journals. J Econ Literat 32:640-666

Liebowitz S, Palmer J (1984) Assessing the relative impacts of economic journals. J Econ Literat 22:77-88

Lubrano M, Bauwens L, Kirman A, Protopopescu C (2003) Ranking economics departments in Europe: a statistical approach. J Eur Econ Assoc 1:1367-1401

Moed H, van Leeuwen (1996) Impact factors can mislead. Nature 381:186

Moed H (2002) The impact-factors debate: the ISI's uses and limits. Nature 415:731-32

Neary J, Mirrlees J, Tirole J (2003) Evaluating economics research in Europe: an introduction. J Eur Econ Assoc 1:1239-1249

Nederdof A (1989) Books and chapters are not to be neglected in measuring research productivity. Am Psychol 44:734-735

Nederdof A, van Raan A (1993) A bibliometric analysis of six economics research groups: a comparison with peer review. Res Policy 22:353-368

Pérez-Díaz V (2005) La crisis endémica de la Universidad española. Claves de razón práctica 158:38-43

Pons J, Tirado D (1999) ¿Quién publica en las revistas españolas de economía? Rev Econ Aplic VII:139-166

Portes R (1987) Economics in Europe. Eur Econ Rev 31:1329-40

Rodriguez D (2006) Publishing performance of Spanish academics: 1970-2004. Spanish Econ Rev $8: 255-270$

Royuela V, Ramos R, Duque JC (2006) La productividad científica en el ámbito de la economía y la empresa en las universidades españolas: producción, productividad, calidad e impacto en el período 1994-2003. Mimeo

Ruiz-Castillo J (2006a) Economics research in Spain during the 1960s: a literature review. Working Paper 06-36, Economic Series 09, Universidad Carlos III

Ruiz-Castillo J (2006b) La investigación en economía en España durante los años 90: una revisión de la literatura. Documento de Trabajo 06-02, Serie de Economía 01, Universidad Carlos III

Sanz Casado E, García Zorita C, García Romero A, Modrego Rico A (1999) La investigación española en economía a través de las publicaciones nacionales e internacionales en el período 1990-95. Rev Econ Aplic VII:113-137

Scott L, Mitias P (1996) Trends in rankings of economics departments in the U.S.: an update. Econ Inquiry 34:378-400

Tombazos C (2005) A revisionist perspective of European research in economics. Eur Econ Rev 49:251-277

Van Damme E (1996) Measuring quality of academia journals and scientific productivity of researchers. Mimeo, Cen Ter, Tilburg University, Tilburg, The Netherlands

Villar A (2003) La evaluación de la investigación en economía. Rev Valenci Econ Hacienda 8:97-133 